\title{
1 Computed tomography imaging-based bitter pit evaluation in apples
}

2 Si Yongsheng1, 2†, Sindhuja Sankaran ${ }^{2+*}$

$3 \quad{ }^{1}$ College of Information Science \& Technology, Agriculture University of HeBei, Baoding, HeHei,

4 China.

$5 \quad$ 2Department of Biological Systems Engineering, Washington State University, Pullman, WA.

6 †qual contributing authors

7 * Corresponding author: Sindhuja Sankaran; Email: sindhuja.sankaran@wsu.edu; Phone: 509-335-

88828.

9

10 Abstract

11 Bitter pit is an economically important physiological disorder in apples resulting in serious

12 economic losses. Current visual assessment techniques are not completely useful in evaluating the

13 extent of bitter pit development as they are limited to external symptoms. An X-ray computer

14 tomography (CT) based imaging and associated image processing algorithm was used to assess the

15 number of bitter pits inside the fruit and on the surface of apples. Samples of 40 healthy and 40

16 bitter pit affected 'Honeycrisp' apples were selected from two different field sites, and scanned with

17 CT equipment on 0, 21 and 63 days after harvest. The results showed that the average number of

18 bitter pits increased both on the surface and inside the fruits with increasing storage period. An

19 average of $42-66 \%$ pits was present inside the apple fruits in bitter pit-affected apples. In addition,

20 most of the newly developed bitter pits in healthy apples appeared within the fruit. Therefore, the

21 usefulness of X-ray CT imaging as an effective phenotyping tool in identifying internal bitter pit and

22 on the surface in the automated manner was demonstrated in this study.

23 Keywords: Phenotyping, Honeycrisp; Image Processing; Apple Disorder 


\section{Nomenclature}

$\begin{array}{lll}26 & a_{i} & \text { constant used in estimating output of an order statistic filter } \\ 27 & \text { CentroidX } & X \text { coordinate of the centre } \\ 28 & \text { Centroid } Y & Y \text { coordinate of the centre } \\ 29 & \text { CT } & \text { computer tomography } \\ 30 & \text { DAH } & \text { days after harvest } \\ 31 & I_{(i, j)} & \text { greyscale value at the point }(i, j) \text { in the image } I \\ 32 & \mathrm{I}_{\mathrm{bw}} & \text { binary image } \\ 33 & I_{\text {min }} & \text { minimum greyscale value in the image } I \\ 34 & J_{(i, j)} & \text { greyscale value at the point }(i, j) \text { in the contrast enhanced image } \\ 35 & \left(I_{(i, j)}-I_{\text {min }}\right)_{\text {max }} & \text { maximum greyscale value in the image }\left(I_{(i, j)} I_{m i n}\right) \\ 36 & P_{\text {num }} & \text { total number of the points on the apple boundary } \\ 37 & \text { QTL } & \text { quantitative trait locus } \\ 38 & \text { WSU } & \text { Washington State University } \\ 39 & y_{k} & \text { output of an order statistic filter of length } N \\ 40 & \rho & \text { radius of each boundary from centre of mass of the apple } \\ 41 & \rho \text {-difference } & \text { difference in radius } \\ 42 & \rho \text {-pulseA } & \text { Normalised } \rho \text {-difference } \\ 43 & \rho \text {-pulseB } & \rho \text {-pulseA after noise removal } \\ & & \end{array}$

\section{1. Introduction}

Bitter pit is a physiological disorder affecting apple fruit production worldwide (Zupan et al.

47 2013; Buti et al., 2015). It is presumed that the bitter pit starts developing during the pre-harvest

48 period and external symptoms may appear during postharvest storage. The typical symptoms

49 include soft, circular, and discrete pits in the cortical flesh resulting from plasma membrane

50 breakdown with regions surrounding the pits turning brown and desiccated (Faust \& Shear, 1968;

51 Fuller, 1979). Several factors are believed to influence the bitter pit development in fruits that 
52 include calcium uptake, crop load, and environmental factors such as location, elevation, and

53 temperature differences (Perring \& Jackson, 1975; Van der Boon, 1980; Ferguson \& Watkins, 1983,

54 1992; Perring, 1986; Failla et al., 1990; Witney et al., 1991). Moreover, the susceptibility is also

55 cultivar dependent (Ferguson \& Watkins, 1989). The disorder can result in serious economic losses

56 as the affected fruits cannot be sold in the fresh market.

57 The current bitter pit detection is limited to visual assessment (Pesis et al., 2010; de Freitas et

58 al., 2013). However, this assessment is not completely useful as bitter pit may be present or can

59 develop inside the fruit without any external symptoms during transportation and storage in the

60 packaging facility. Similarly, visual ratings are used to phenotype apples for identifying genes

61 associated with bitter pit susceptibility or tolerance (Voltz et al., 2006; Evans et al., 2011; Kumar et

62 al., 2013; Brazek, 2013; Buti et al., 2015; de Freitas et al., 2015). For example, Buti et al. (2015)

63 scored the bitter pit susceptibility in 364 seedlings (cross between 'Redchief' and 'X6688' with 'M.9'

64 rootstock) on a scale of 0-4, ranging from non-symptomatic to very highly symptomatic for two

65 seasons at full apple maturity. The marker-based restricted multiple quantitative trait locus (QTL)

66 method was utilised with bitter pit incidence association as cofactor to discover minor QTL through

67 linkage. The study found that putative loci influencing the bitter pit symptoms were not stable,

68 which was believed to be an artefact of phenotyping process. The research recommended the

69 development of a more precise phenotyping technique as one of the potential ways that will allow

70 identification of the genes associated with the disorder. Therefore, there is a need for non-

71 destructive sensing of bitter pit in apples for both precise phenotyping and sorting on the

72 commercial packaging lines.

The non-destructive sensing techniques that are being investigated include fluorescence

74 imaging (Lötze et al., 2006), hyperspectral imaging (Nicolaï et al., 2006), and computer tomography

75 (CT) imaging (Jarolmasjed et al., 2016). Nonetheless, these techniques are useful for evaluating the

76 presence and absence of bitter pit, rather than a quantitative data representing internal (non- 
77 symptomatic) and external (symptomatic) bitter pits. This data can especially be very useful for

78 genetics and breeding applications. Such information may also be used to decide the effective

79 storage index and duration of harvested fruits in storage by fruit packaging units. With this goal, the

80

81

82

83

84

85

86

87

88

89

90

91

92

93

94

95

96

97

98

99

100

specific study objective was to develop a robust image processing algorithm to assess the number of internal and external bitter pits in apples scanned using X-ray CT equipment.

\section{Materials and methods}

\subsection{Fruit sampling and data acquisition}

Healthy and bitter pit affected 'Honeycrisp' apples (20 each) were selected from two different field sites in Walla Walla County, WA, USA for this study; Burbank (location-1) and Prescott (location-2). The freshly harvested fruits were transferred to Washington State University (WSU), Pullman, WA, cleaned, and sorted in a packaging box. The apples were stored at $5^{\circ} \mathrm{C}$ for up to 63 days. X-ray CT imaging was performed at Veterinary Medicine Hospital, WSU using Toshiba Aquilion $^{\text {tm }} 16$ CT tomograph (Tustin, CA, USA). The fruits were scanned multiple times during 63 days of storage. 0,21 , and 63 days after harvest (DAH) data were used for analysis. More details on data collection can be found in Jarolmasjed et al. (2016). CT images were taken from three different directions: longitudinal, transversal and sagittal, with $3 \mathrm{~mm}$ thickness between each scan and same number of total scans from each box. Images from longitudinal CT scan were used in this study.

\subsection{Image analysis}

Pertinent CT images were processed and analysed using MATLAB (2014b) and the Image

Processing Toolbox. Images were segmented manually for identifying bitter pits present in individual apple. The total number of pits on the surface (cuticle) and inside the fruit was determined for healthy and bitter pit apples (Fig. 1) based on the method described below. 
2.2.1. Bitter pit on the apple surface

The pixel intensities of CT images were normalised using linear transformation such that the intensity ranged from 0 to 1 using following equation:

$$
I_{(i, j)}=\frac{I_{(i, j)}-I_{\min }}{\left(I_{(i, j)}-I_{\min }\right)_{\max }}(i \in(1, m), j \in(i, n))
$$

121 where, CT image $I$ is $m \times n$ pixel image, $I_{(i, j)}$ is the greyscale value at the point $(i, j)$ in $I ; I_{\min }$ is the minimum greyscale value in the image $I .\left(I_{(i, j)}-I_{\min }\right)_{\max }$ is the maximum greyscale value in the image $\left(I_{(i, j)}-I_{\min }\right)$. Following this step, contrast enhancement was applied to increase CT image quality.

$$
J_{(i, j)}=\left\{\begin{array}{c}
0 \\
\frac{I(i, j)-a}{b-a} \\
1
\end{array}\right\} \begin{gathered}
I(i, j) \leq a \\
I(i, j) \in(a, b) \\
I(i, j) \geq b
\end{gathered}
$$

where, $J_{(i, j)}$ is the greyscale value at the point $(i, j)$ in the contrast enhanced image. $(0, a)$ and $(b, 1)$ denote the bottom $1 \%$ and the top $1 \%$ of all pixel values, respectively.

The apple contour image (Fig. 1a) was utilized for bitter pit detection on the surface. To achieve this, Otsu thresholding technique (Otsu, 1975) was applied to create a binary image (Fig. 1b) from the original greyscale image for each apple. Noise from packaging materials (tray and box) was eliminated by removing small objects ( $<600$ pixels) from the binary image. The pit regions in a fruit resulting from fruit core and bitter pits inside the fruit were eliminated by filling in those pixels. Fig. 1c shows the apple image without small objects, fruit core, and pits inside the fruit. The boundary of the fruit was traced from the image (Gonzalez \& Woods, 1975). The centre of mass of the apples (i.e. centre of the apple) was determined using the following equations, in which the size of the binary image $\mathrm{I}_{\mathrm{bw}}$ is $m 1 \times n 1$ :

$$
\begin{aligned}
& \text { CentroidX }=\frac{\sum_{i=1}^{m 1} \sum_{j=1}^{n 1} i_{b w(i, j)}}{\sum_{i=1}^{m 1} \sum_{j=1}^{n 1} I_{b w(i, j)}} \\
& \text { CentroidY }=\frac{\sum_{i=1}^{m 1} \sum_{j=1}^{n 1} j I_{b w}(i, j)}{\sum_{i=1}^{m 1} \sum_{j=1}^{n 1} I_{b w(i, j)}}
\end{aligned}
$$


123 where, Centroid $X$ and Centroid $Y$ are the coordinates of the centre. $I_{b w(i, j)}$ is the pixel value (0 or 1$)$ at

124 the point $(i, j)$ in the binary image. Following this, the radius $(\rho$, polar distance) of each boundary

125 point from the centre of mass of the apples (origin of distance coordinate) was calculated. During

126 continuous calculation of the polar distances (radii), presence of bitter pit will result in a sudden

127 decrease in the radius. Therefore, to estimate this sudden change in radius, the difference between

128 the radius of first boundary point ( $i$ ) and every fourth boundary point $(i+3)$ was estimated, using

129 the following equation:

130

$$
\rho \text {-difference }(i)=\rho(i+3)-\rho(i)
$$

131 where, $\rho$-difference refers to difference in radius, and $i$ can range from 1 to $P_{\text {num. }} P_{\text {num }}$ is the total

132 number of the points on the apple boundary. For example, the difference between $i$ and $i+3$

133 boundary points as shown in Fig. 2a, will be $x$-y. The $\rho$-difference was normalised as $\rho$-pulseA. $\rho$ -

134 pulseA was 1 when $\rho$-difference was greater than or equal to 2 , else $\rho$-difference was 0 (Fig. 2b). In

135 regions of calyx and stem end, a gradual decrease in radius $\rho$ was observed with few noises

136 resulting from anomalies. For example, $\rho$-pulseA between -30 and -150 represents stem end region

137 of the apple, while $\rho$-pulseA between 70 and 120 represents calyx end, as shown in Fig. $2 \mathrm{~b}$. The $\rho$ -

138 pulseA was converted into $\rho$-pulseB peaks by removing some of these noises and finally utilising the

139 data for detecting number of bitter pits on the surface.

$140 \quad$ 2.2.2. Bitter pit inside the apple

141 Greyscale image was used to determine the total number of pits inside the apples (Fig. 1d). To

142 isolate the background from each apple, grayscale image was multiplied with the contour image.

143 The pixel values outside the apples were converted to zero. To detect the bitter pits, 3-by-3

144 maximum and 3-by-3 minimum filters were implemented to the multiplied apple greyscale image

145 separately. Both the maximum filter and minimum filter are a form of the order statistic filter. The 146 output of an order statistic filter of length $N$ operating on a sequence $\left(x_{i}\right)$ for $N$ odd is given by

$147 \quad y_{k}=\operatorname{OSF}\left(\left\{x_{i}\right\}_{j=k-M}^{k+M}=\sum_{i=1}^{N} a_{i} x_{(i)}^{k}\right.$ 
where $M=(N-1) / 2$ and $\mathrm{x}_{(\mathrm{i})}{ }^{\mathrm{k}}$ are the order statistics of $x_{k-M} \ldots X_{k \ldots} \ldots X_{k+m}$. The $a_{i}$ values are constants that

149 may be chosen for a particular application (Bovik et al., 1983). A sample calculation of maximum

150 and minimum filters is shown below:

$$
\left[\begin{array}{ccc}
12 & 2 & 5 \\
5 & 7 & 5 \\
10 & 2 & 3
\end{array}\right]=\left[\begin{array}{ccc}
12 & 2 & 5 \\
5 & 12 & 5 \\
10 & 2 & 3
\end{array}\right]
$$

152

$$
\left[\begin{array}{ccc}
12 & 2 & 5 \\
5 & 7 & 5 \\
10 & 2 & 3
\end{array}\right]=\left[\begin{array}{ccc}
12 & 2 & 5 \\
5 & 2 & 5 \\
10 & 2 & 3
\end{array}\right]
$$

Minimum filter image was subtracted from the maximum filter image to acquire the differential image, which clearly presented the pit areas, boundary, and apple core region with higher pixel values (Fig. 1e). Following this step, all the pixels on the boundary and within the 3-by-3 neighbourhood of the boundary pixels were converted into background pixel values. The resulting 157 image was with pits and apple core only (without boundary, Fig. 1f). No bitter pit was observed in 158 the fruit core. Therefore, the core was eliminated from the central region of the apple. The central region was defined as centre of the individual apple image having a radius one-fifth of the apple diameter (the diameter of a circle with the same area as the apple, Fig. 1g). An area threshold of 1615,000 pixels was applied to judge if there is a core inside the apple. Resulting image without the 162 core was converted into binary image using a pixel value threshold of 30 (Fig. 1h). The area of each 163 bitter pit was then estimated. For the pits with area less than 4 pixels, the bitter pit pixels were 164 converted into background. Additionally, length and width ratio of individual bitter pit was 165 calculated with rectangular box fit (Fig. 1i) and pits with ratio greater than 4 were considered for 166 further analysis. It eliminated possibilities of noise near the boundary region and some extent of 167 mechanical bruise injury. Following which, grey difference image (Fig. 1j) was also developed to 168 confirm the bitter pit regions. The average grey pixel value of each bitter pit in the differential 169 image was calculated. The complement of the differential image was used to simplify the image 170 representation. 
In addition to core, the stem end and calyx was eliminated from the images (strip removal). The

172 minimum radius in the contour image was utilized to identify the stem and calyx end for

173 determining the strip region. Stem end and calyx end determination was based on the difference

174 between the average radius and the minimum radius. The coordinates of the points on the

175 boundary were converted to polar coordinates. In the range of 0 to $180^{\circ}$ (bottom half of apple), the

176 minimum radius caused by calyx was estimated. If the difference between the average and

177 minimum radius was larger than a threshold ( $>6$ units), the point was marked as calyx end.

178 Similarly, the stem end was detected in the range of 0 to $-180^{\circ}$. After both ends (calyx and stem)

179 were detected, a line was drawn through the two ends, and termed as the centre line. Two parallel

180 lines on either sides of the centre line were developed such that the distance between them was 20

181 pixels. This region between the parallel lines was defined as the strip region (Fig. 1k) and

182 eliminated as background. After removing all the background, the remaining spots were bitter pits

183 inside the apples (Fig. 11). The total number of pits and pit area (number of pixels showing

184 anomalies) was computed as the output from the image processing algorithm. Using the developed

185 algorithm, The CT Scan images were batch processed and the resulting data was analysed using the 186 SAS ${ }^{\circledR}$ statistical software (ver. 9.2, SAS Institute Inc., Cary, NC, USA).

\section{Results and discussion}

\subsection{Bitter pit on the apple surface}

The minimum, average, and maximum number of bitter pits on the apple surface (20 samples)

191 at different time periods after harvest for two field locations are presented in Fig. 3. At the

192 beginning of the study (DAH=0), the healthy apples did not have any bitter pits on the surface,

193 while the number of bitter pits on the affected apples ranged up to a maximum of 40 and 28 at

194 locations-1 and -2, respectively. The maximum number of bitter pits eventually increased up to 60

195 in location-2 at 63 DAH. Interestingly, the maximum number of pits on the surface of the fruit 
remained almost constant at location-1. However, the average number of bitter pits increased from

197 about 5 to 15 pits at 63 DAH at location-1. In case of location-2, the average number of pits

198 increased from about 7 to 23 during $63 \mathrm{DAH}$ storage. The trend clearly indicated that bitter pit

199 affected apples could further develop bitter pits during storage. In a real-world scenario, if bitter pit

200 apples were identified, the produce will be sent to processing immediately before the condition

201 becomes worse.

202 In bitter pit affected apples, the maximum number of bitter pits decreased between 21 DAH to

$20363 \mathrm{DAH}$ in few samples. The possible reason for this observation could be because of two

204 neighbouring bitter pits merging into a single pit during disorder progression in storage. This

205 would lead to single count as predicted using the developed algorithm. This decrease in total

206 number of bitter pits from 21 DAH to 63 DAH was only observed in 5 (of 20) apples in location-1

207 and 4 (of 20) apples in location-2.

208 In regard to the healthy apples, the average number of bitter pits was less than 1 in both

209 locations. However, in case of location-2, an apple showed 6 bitter pits on 21 DAH, which reduced

210 to 2 pits at $63 \mathrm{DAH}$. The pits close to each other may have merged. After 63 days of storage, 3 (of

21120 ) and 2 (of 20) healthy apples had developed bitter pits from location-1 and -2, respectively. Such

212 image processing based trends were consistent with ground reference data (visual observation).

213 This indicates the potential of utilising CT imaging based technique for identifying the bitter pits on 214 the surface in an automated manner.

\subsection{Bitter pit inside the apple}

Table 1 summarises the data on the total number of bitter pits per apple as detected by the

218 image processing algorithm. Average number of pits in bitter pit-affected apples increased from 9

219 to 19 and 18 to 19 during 63 DAH storage in location-1and location-2 sampled fruits, respectively.

220 Note that the average number of pits detected increased from 0 to $21 \mathrm{DAH}$, which again decreased 
221 from 21 to $63 \mathrm{DAH}$. The decrease in number of bitter pits could be attributed to merging of pits as

222 observed in the bitter pits present in the surface. In addition, the pits present in apple subsurface

223 may have merged into the cuticle surface. The algorithm would detect these newly developed pits

224 as surface pits rather than internal pits. The number of apples with a decrease in the total number

225 of bitter pits inside from 21 DAH to 63 DAH were 13 and 14 of 20 apples in location-1 and -2 ,

respectively. This trend also indicates that the development of bitter pits inside the fruit is at a

227 much faster rate than the surface bitter pits.

228

In case of healthy apples, the average number of bitter pits was less than 1 at $0 \mathrm{DAH}$. The

average number of bitter pits inside the fruit increased up to 7 at $63 \mathrm{DAH}$. One of the challenges in

the image processing was the complete elimination of regions with internal bruising. The bruising was significant in the fruits from location-1. Fruit bruising could have occurred during harvest and transportation of fruits from field to the laboratory. Usually, the bruising symptoms develops few days after harvest. In regard to the apple production and management practices, bruised apples would result in similar economic losses as that of bitter pit-affected apples, and CT-based image acquisition and processing to identify all internal defects can be beneficial. Ideally, such fruits will be sorted on the packaging line to be sent to processing industry rather than to the fresh market.

237 For healthy samples from location-2, 10 of the 20 apples developed internal bitter pits during 63 238 days of storage, while only 2 of those apples developed external symptoms. This further signifies the potential of CT-based imaging technique towards identifying internal bitter pit symptoms.

The algorithm also estimated the pit area in each layer of an apple (Fig. 4). For samples from

241 location-1, the total pit area inside the affected apples ranged from 7-2309 pixels at 0 DAH and 20-

2423287 pixels at 63 DAH. Similarly, for location-2, the corresponding range was from 10-3573 at 0

243 DAH and 91-3533 at 63 DAH. In regard to the healthy apples in location 2, the total area of newly 244 developed bitter pits ranged from 6 to 203 pixels, indicating that these pits were much fewer and 245 smaller than those in the affected apples. Between $21 \mathrm{DAH}$ and $63 \mathrm{DAH}$, there was some decrease in 
the pit area, which could be associated with shrinkage of pits caused by loss of moisture during storage or merging of internal subsurface pits to the surface as mentioned above.

\subsection{Bitter pit distribution within a fruit}

Overall, 42 to $66 \%$ of the pits in the affected fruit were present inside rather than on the fruit surface (Fig. 5). It indicates that pits seen on the surface of bitter pit affected apples, only represent about $50 \%$ of the total bitter pits presents in the apple fruit. In some apples, the number of internal pits could range close to $100 \%$ of the all the bitter pits present. In the healthy apples from location 2 at 63 DAH, expect 2 samples (having surface symptoms), 100\% of newly developed bitter pits were from inside as discussed above. This signifies the importance of CT-based imaging for high-throughput accurate phenotyping to support breeding efforts to develop bitter pit tolerant varieties. In addition, the technique can also be confidently applied for identifying bitter pits inside the fruit during initial stage of development in the processing lines.

\section{Conclusions}

This work evaluates the feasibility of acquiring qualitative and quantitative data on bitter pit occurrences in apples using X-ray CT-based imaging with a custom-developed image processing algorithm. The CT-based imaging has not been used for acquiring quantitative information during post-harvest produce evaluation. The acquired results indicate the potential of utilizing the nondestructive CT-based imaging technique for thorough evaluation of internal produce quality, which can be very useful during processing as well as in plant breeding studies. The results indicated that most of bitter pit starts developing inside the fruit, while the external symptoms are absent.

Identification of such internal symptoms can be greatly beneficial to the processing industry as they can prevent packaging and transportation of defective products. In addition, the technique can also be applied to other specialty crops for internal disorder evaluation. 


\section{Acknowledgements}

273 The authors are grateful to Ms. Sanaz Jarolmasjed, Mr. Carlos Zuniga, and Dr. Tom Wilkinson from

274 WSU for their assistance during data collection. This activity was funded by Washington State

275 Department of Agriculture (WSDA) -Specialty Crop Block Grant Program (SCBGP), and partly

276 supported by the USDA National Institute for Food and Agriculture Hatch Project WNP00821 and

277 programme of study abroad for young teachers by Agricultural University of Hebai. We would also

278 like to thank fruit growers; Borton Fruit, Dave Hovde, Dan Borton, and Sky Johnson for their help

279 during this study.

280

281

\section{REFERENCES}

Blazek, J. (2013). Comparative Study of Apple Cultivars Bred in Holovousy, Czech Republic. Journal of Plant Studies, 2(2), 113.

Bovik, A. C., Huang, T. S., \& Munson Jr, D. C. (1983). A generalization of median filtering using linear combinations of order statistics. Acoustics, Speech and Signal Processing, IEEE Transactions on, 31(6), 1342-1350.

287 Buti, M., Poles, L., Caset, D., Magnago, P., Fernandez, F. F., Colgan, R. J., \& Sargent, D. J. (2015).

288 Identification and validation of a QTL influencing bitter pit symptoms in apple (Malus× 289 domestica). Molecular Breeding, 35(1), 1-11.

290 de Freitas, S. T., do Amarante, C. V. T., \& Mitcham, E. J. (2015). Mechanisms regulating apple cultivar 291 susceptibility to bitter pit. Scientia Horticulturae, 186, 54-60.

292 de Freitas, S. T., do Amarante, C. V., Dandekar, A. M., \& Mitcham, E. J. (2013). Shading affects flesh 293 calcium uptake and concentration, bitter pit incidence and other fruit traits in "Greensleeves" 294 apple. Scientia Horticulturae, 161, 266-272. 
Evans, K., Guan, Y., Luby, J., Clark, M., Schmitz, C., Brown, S. \& Iezzoni, A. 2011. Large-scale standardized phenotyping of apple in RosBREED. In IV International Conference Postharvest Unlimited 2011945 (pp. 233-238).

Failla, O., Treccani, C. P., \& Mignani, I. (1990). Water status, growth and calcium nutrition of apple trees in relation to bitter pit. Scientia Horticulturae, 42(1), 55-64.

Faust, M., \& Shear, C. B. (1968). Corking disorders of apples: A physiological and biochemical review. The Botanical Review, 34(4), 441-469.

Ferguson, I. B., \& Watkins, C. B. (1983). Cation distribution and balance in apple fruit in relation to calcium treatments for bitter pit. Scientia Horticulturae, 19(3), 301-310.

Ferguson, I. B., \& Watkins, C. B. (1989). Bitter pit in apple fruit. Horticultural Reviews, Volume 11, 289-355.

Ferguson, I. B., \& Watkins, C. B. (1992). Crop load affects mineral concentrations and incidence of bitter pit inCox's Orange Pippin'apple fruit. Journal of the American Society for Horticultural Science, 117(3), 373-376.

Fuller, M. M. 1979. Cell ultrastructure in apple fruits in relation to calcium concentration and fruit quality. In Symposium on Mineral Nutrition and Fruit Quality of Temperate Zone Fruit Trees 92 (pp. 51-56).

Gonzalez, R. C., \& Woods, R. E. (2007). Digital image processing 3rd edition.

Jarolmasjed, S., Espinoza, C. Z., Sankaran, S., \& Khot, L. R. (2016). Postharvest bitter pit detection and progression evaluation in 'Honeycrisp'apples using computed tomography images. Postharvest Biology and Technology, 118, 35-42.

Kumar, S., Garrick, D. J., Bink, M. C., Whitworth, C., Chagné, D., \& Volz, R. K. (2013). Novel genomic approaches unravel genetic architecture of complex traits in apple. BMC genomics, 14(1), 393. 
Lötze, E., Huybrechts, C., Sadie, A., Theron, K. I., \& Valcke, R. M. (2006). Fluorescence imaging as a non-destructive method for pre-harvest detection of bitter pit in apple fruit (Malus domestica Borkh.). Postharvest Biology and Technology, 40(3), 287-294.

Nicolaï, B. M., Lötze, E., Peirs, A., Scheerlinck, N., \& Theron, K. I. (2006). Non-destructive measurement of bitter pit in apple fruit using NIR hyperspectral imaging. Postharvest Biology and Technology, 40(1), 1-6.

Otsu N. (1975). A threshold selection method from gray-level histograms[J]. Automatica, 11(285296): 23-27.

Perring, M. A. (1986). Incidence of bitter pit in relation to the calcium content of apples: problems and paradoxes, a review. Journal of the Science of Food and Agriculture, 37(7), 591-606.

Perring, M. A., \& Jackson, C. H. (1975). The mineral composition of apples. Calcium concentration and bitter pit in relation to mean mass per apple. Journal of the Science of Food and Agriculture, 26(10), 1493-1502.

Pesis, E., Ebeler, S. E., de Freitas, S. T., Padda, M., \& Mitcham, E. J. (2010). Short anaerobiosis period prior to cold storage alleviates bitter pit and superficial scald in Granny Smith apples. Journal of the Science of Food and Agriculture, 90(12), 2114-2123.

Van der Boon, J. (1980). Prediction and control of bitter pit in apples. I. Prediction based on mineral leaf composition, cropping levels and summer temperatures. Journal of Horticulture Science, 55(3), 307-312.

Volz, R. K., Alspach, P. A., Fletcher, D. J., \& Ferguson, I. B. (2006). Genetic variation in bitter pit and fruit calcium concentrations within a diverse apple germplasm collection. Euphytica, 149(1-2), $1-10$

Witney, G. W., Kushad, M. M., \& Barden, J. A. (1991). Induction of bitter pit in apple. Scientia Horticulturae, 47(1), 173-176. 
342 Zupan, A., Mikulic-Petkovsek, M., Cunja, V., Stampar, F., \& Veberic, R. (2013). Comparison of

343 phenolic composition of healthy apple tissues and tissues affected by bitter pit. Journal of

$344 \quad$ Agricultural and Food Chemistry, 61(49), 12066-12071.

345 

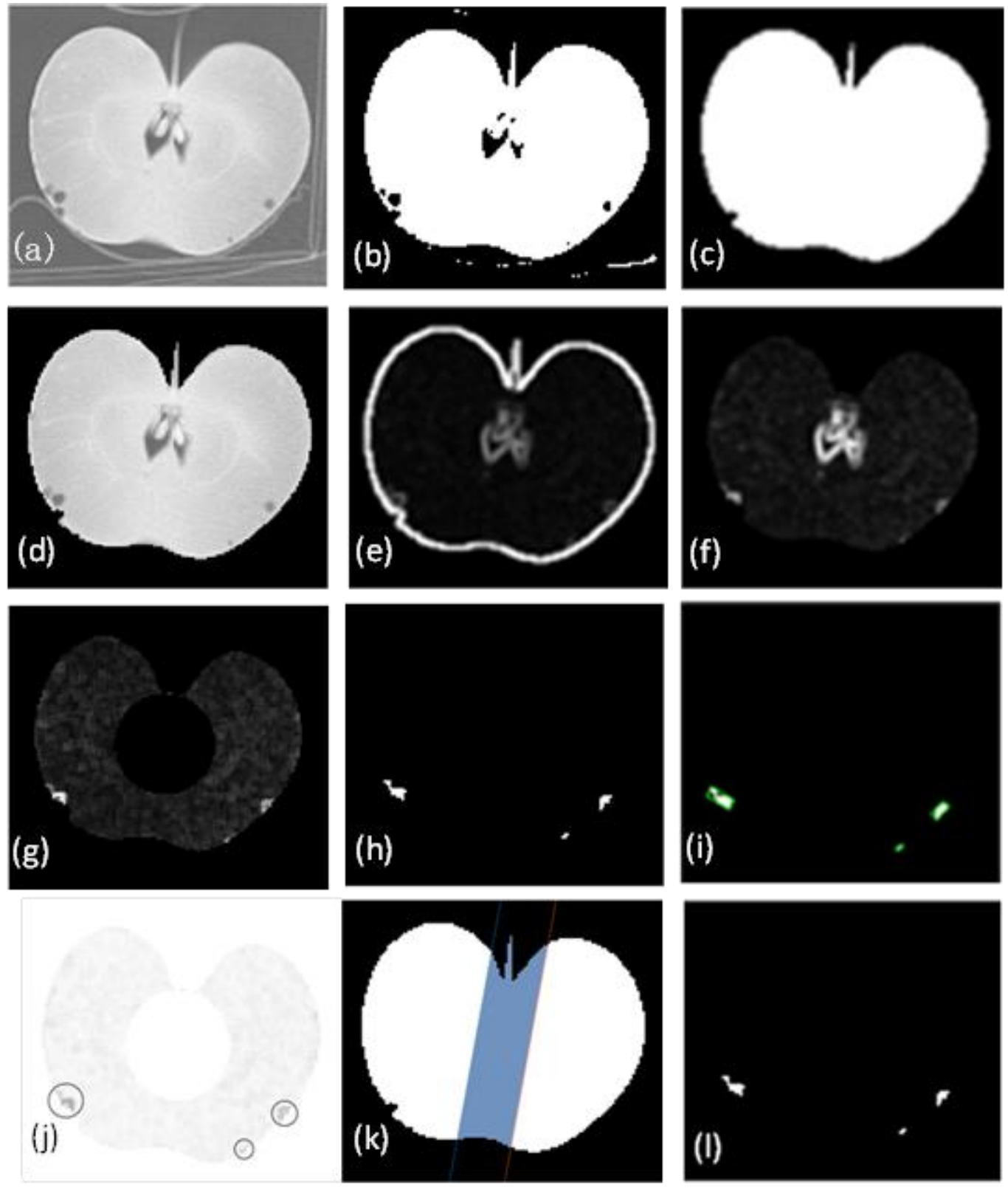

347 Fig. 1- Apple images generated for bitter pit detection on the surface and inside the fruit. (a)

348 Raw segmented image, (b) binary image derived from segmented image, (c) binary image

349 after elimination of small objects (<600 pixels), core, and pits inside the apple (this image

350 was used for estimating the number of bitter pit on the outer surface by calculating the

351 radius from mass centre to the boundary), (d) raw greyscale image used for estimating

352 bitter pits inside the apples, (e) differential image after applying minimum and maximum 
353 filter on the greyscale image, (f) image after boundary elimination from the differential

354 image, (g) image after core elimination, (h) binary image acquired from differential image

355 after boundary and core elimination, (i) image determining length-width ratio using

356 rectangular fit, (j) grey difference image, (k) image determining the strip region in the apple

357 image, and (1) the final binary image used for calculating total number of bitter pits and their

358 area inside the fruit. 
(a) Radius ( $\rho$ ) and $\rho$-difference estimation

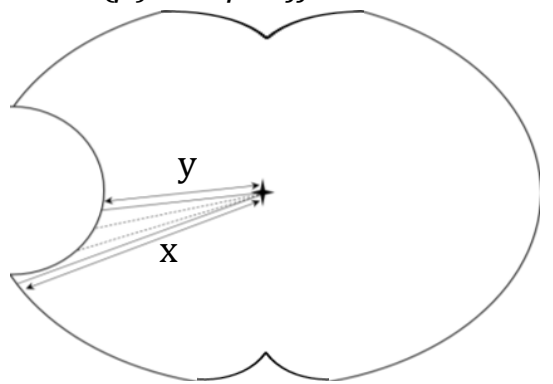

(b) Pit identification from $\rho$ and $\rho$-difference values
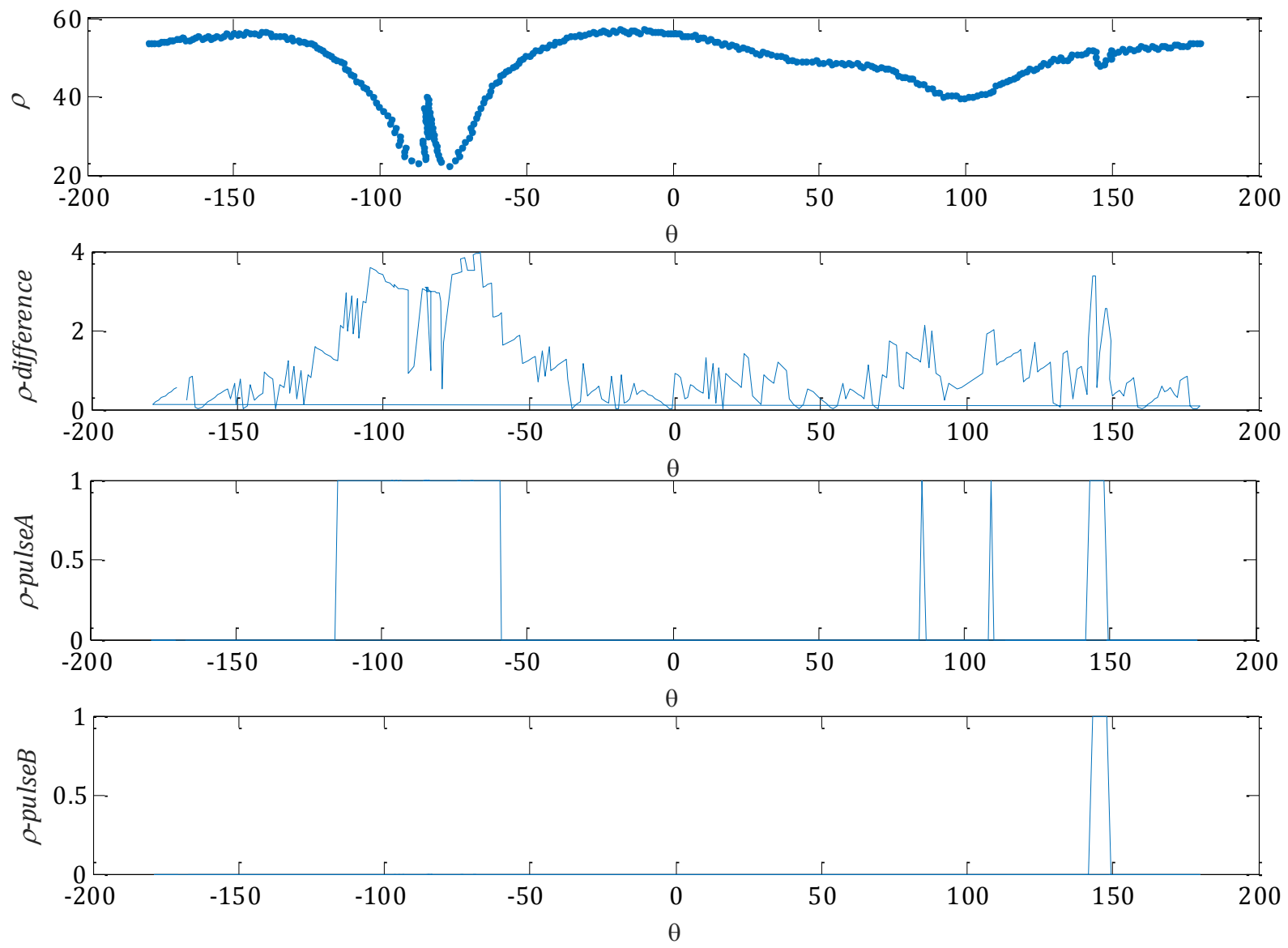

360 Fig. 2- (a) Schematics illustrating the $\rho$-difference estimation from the radius $(\rho)$ between the

361 boundary and the centre of the apple. In an event of bitter pit occurrence on the apple

362 surface, radius $y$ will be less than radius $x$. $\rho$-difference will be equal to $y$-x. (b) Pit

363 identification from $\rho$ and $\rho$-difference values. Radius of each boundary point from the mass centre of the apples, the regions between -100 to -50 and 75 to $125(\theta)$ represent stem and 
365 calyx ends of the apple, respectively. $\rho$-difference showing possible pit locations, $\rho$-pulseA

366 after normalisation ( 0 or 1) of $\rho$-difference, and $\rho$-pulseB after noise removal. 
(a) Location-1 Number of Bitter Pits $\begin{array}{llllll}10 & 20 & 30 & 40 & 50 & 60\end{array}$

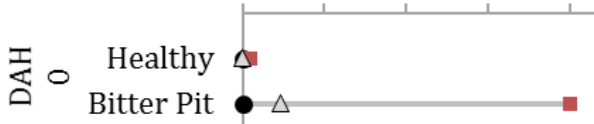

志

至 $\tilde{b}$ Bitter Pit

- Minimum $\backsim$ Maximum $\triangle$ Average (b) Location-2 Number of Bitter Pits $\begin{array}{llllll}10 & 20 & 30 & 40 & 50 & 60\end{array}$

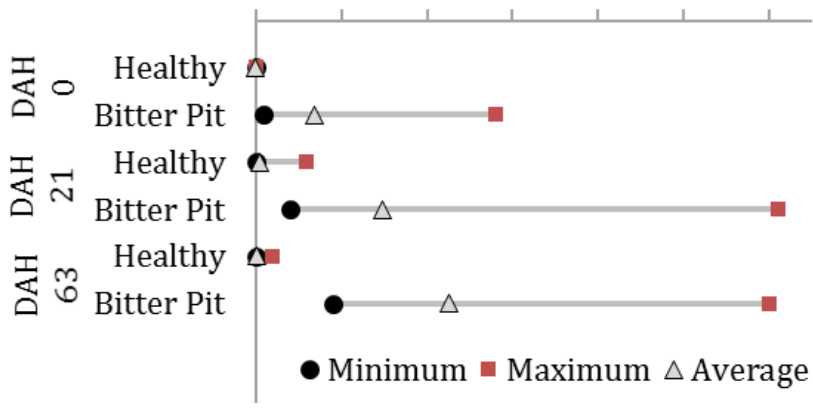

Fig. 3- Bitter pit progression on the surface of healthy and bitter pit apples from both locations. 


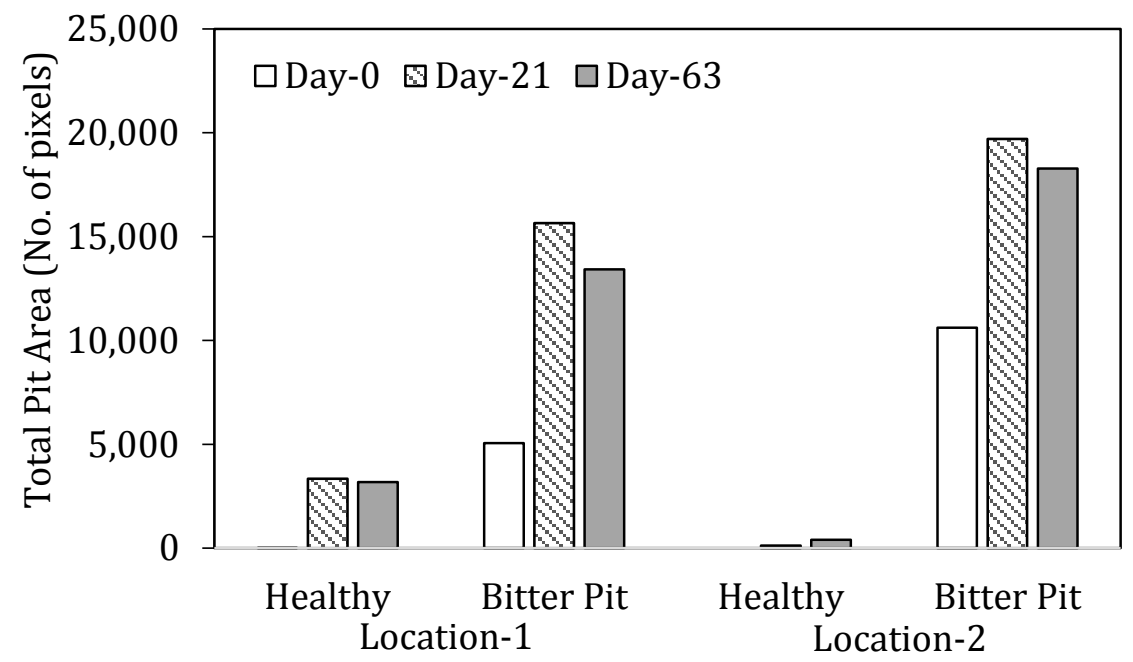

370

371 Fig. 4- Total pit area (sum of all pits from 20 samples in each category) inside healthy and 372 bitter pit affected apples from both locations. 


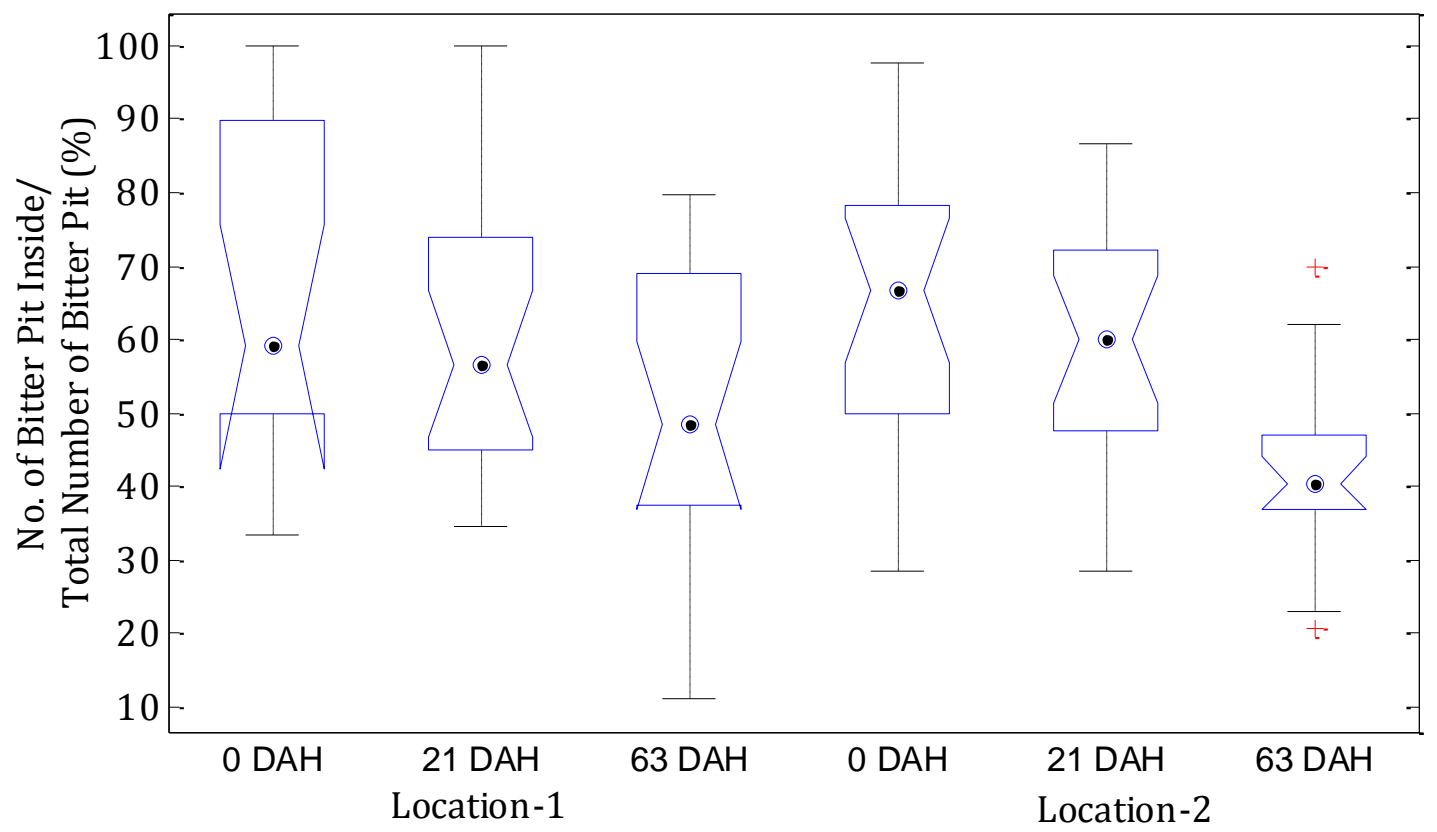

373

374 Fig. 5- Boxplot showing the number of bitter pits inside the fruit with respect to total

375 number of pits in a given bitter pit-affected apple from both locations. The 'central box'

376 represents the central $50 \%$ of the data with lower and upper boundary lines representing

377 the $25 \%$ and $75 \%$ quantile of the data. A circular dot indicates the median of the data; while

378 the two vertical lines extending from central box indicate the remaining data range. The

379 outliers are marked as ' + '. 
Table 1- Total number of bitter pits detected by the developed image processing algorithm

381 inside the healthy (H) and bitter pit (BP) affected apples from both field locations during 63

DAH storage period.

\begin{tabular}{|c|c|c|c|c|c|c|c|c|c|c|c|c|}
\hline \multirow{4}{*}{$\begin{array}{c}\text { Location } \\
\text { DAH } \\
\text { Apple No. }\end{array}$} & \multicolumn{12}{|c|}{ Number of pits inside the fruit } \\
\hline & \multicolumn{6}{|c|}{1} & \multicolumn{6}{|c|}{2} \\
\hline & \multicolumn{2}{|c|}{0} & \multicolumn{2}{|c|}{21} & \multicolumn{2}{|c|}{63} & \multicolumn{2}{|c|}{0} & \multicolumn{2}{|c|}{21} & \multicolumn{2}{|c|}{63} \\
\hline & $\mathrm{H}$ & $\mathrm{BP}$ & $\mathrm{H}$ & $\mathrm{BP}$ & $\mathrm{H}$ & $\mathrm{BP}$ & $\mathrm{H}$ & $\mathrm{BP}$ & $\mathrm{H}$ & $\mathrm{BP}$ & $\mathrm{H}$ & $\mathrm{BP}$ \\
\hline 1 & 1 & 3 & 9 & 9 & 6 & 12 & 0 & 23 & 0 & 39 & 2 & 47 \\
\hline 2 & 0 & 0 & 7 & 27 & 12 & 66 & 0 & 94 & 1 & 100 & 2 & 38 \\
\hline 3 & 0 & 6 & 3 & 4 & 6 & 3 & 0 & 30 & 0 & 15 & 0 & 8 \\
\hline 4 & 0 & 1 & 1 & 5 & 4 & 10 & 0 & 40 & 2 & 19 & 5 & 8 \\
\hline 5 & 0 & 2 & 1 & 8 & 6 & 3 & 0 & 28 & 1 & 18 & 1 & 8 \\
\hline 6 & 0 & 0 & 1 & 13 & 1 & 27 & 0 & 34 & 3 & 60 & 0 & 31 \\
\hline 7 & 0 & 0 & 13 & 9 & 22 & 27 & 0 & 6 & 0 & 6 & 3 & 4 \\
\hline 8 & 0 & 4 & 0 & 31 & 0 & 26 & 0 & 2 & 1 & 6 & 1 & 6 \\
\hline 9 & 0 & 0 & 3 & 1 & 5 & 0 & 0 & 18 & 0 & 17 & 0 & 11 \\
\hline 10 & 0 & 52 & 8 & 151 & 6 & 71 & 0 & 15 & 0 & 31 & 0 & 23 \\
\hline 11 & 0 & 54 & 1 & 42 & 2 & 24 & 0 & 1 & 0 & 2 & 0 & 9 \\
\hline 12 & 0 & 0 & 18 & 3 & 9 & 1 & 0 & 15 & 0 & 48 & 0 & 41 \\
\hline 13 & 0 & 0 & 8 & 3 & 10 & 5 & 0 & 2 & 0 & 25 & 1 & 8 \\
\hline 14 & 0 & 6 & 0 & 3 & 0 & 3 & 0 & 7 & 0 & 11 & 0 & 7 \\
\hline 15 & 0 & 4 & 9 & 9 & 16 & 3 & 0 & 2 & 0 & 6 & 0 & 9 \\
\hline 16 & 0 & 1 & 0 & 2 & 1 & 4 & 0 & 8 & 0 & 88 & 1 & 26 \\
\hline 17 & 0 & 5 & 1 & 13 & 0 & 7 & 0 & 7 & 2 & 7 & 3 & 5 \\
\hline 18 & 0 & 17 & 26 & 69 & 13 & 30 & 0 & 11 & 0 & 15 & 0 & 18 \\
\hline 19 & 0 & 13 & 14 & 18 & 5 & 10 & 0 & 24 & 1 & 35 & 2 & 18 \\
\hline 20 & 0 & 18 & 28 & 39 & 11 & 47 & 0 & 1 & 0 & 7 & 0 & 49 \\
\hline Minimum & 0 & 0 & 0 & 1 & 0 & 0 & 0 & 1 & 0 & 2 & 0 & 4 \\
\hline Average & 0 & 9 & 7 & 23 & 7 & 19 & 0 & 18 & 1 & 28 & 1 & 19 \\
\hline Maximum & 1 & 54 & 28 & 151 & 22 & 71 & 0 & 94 & 3 & 100 & 5 & 49 \\
\hline
\end{tabular}

